Georgia State University

ScholarWorks @ Georgia State University

1985

\title{
Ethnic Segmentation of Real Estate Agent Practice in the Urban Housing Market
}

Risa Palm

Georgia State University, risapalm@gsu.edu

Follow this and additional works at: https://scholarworks.gsu.edu/geosciences_facpub

Part of the Geography Commons, and the Geology Commons

\section{Recommended Citation}

Palm, Risa, "Ethnic Segmentation of Real Estate Agent Practice in the Urban Housing Market" (1985).

Geosciences Faculty Publications. 14.

https://scholarworks.gsu.edu/geosciences_facpub/14

This Article is brought to you for free and open access by the Department of Geosciences at ScholarWorks @ Georgia State University. It has been accepted for inclusion in Geosciences Faculty Publications by an authorized administrator of ScholarWorks @ Georgia State University. For more information, please contact scholarworks@gsu.edu. 


\title{
Ethnic Segmentation of Real Estate Agent Practice in the Urban Housing Market
}

\author{
Risa Palm \\ College of Arts and Sciences, University of Colorado, Boulder, CO 80309.
}

\begin{abstract}
This study investigated the extent to which the real estate industry is segmented along racial or ethnic lines. A 1982 survey of Anglo, black, and Hispanic real estate agents in the Denver metropolitan area showed ethnic segmentation in the structure of real estate business practice. Sellers select real estate agents at least partially on the basis of a common ethnicity, ethnicity affects the size and location of territories in which an agent obtains listings, and an agent's network of business contacts is limited by and is shaped by the ethnicity of the agent. Ethnicity therefore adds a further distortion to the spatially biased information set available to real estate agents.
\end{abstract}

Key Words: real estate agents, ethnic segregation, housing market.

The role of real estate agents in filtering information related to the migration decision has been the subject of considerable attention by urban geographers. In the process of linking sellers of property with prospective buyers, real estate agents impart a specialized geographic knowledge.

Previous research has focused on how real estate agents acquire and structure information about the city and how they use this information to direct the nature and pace of search (Caruso 1976; Clark and Smith 1979; Palm 1976). The research reported here deals with how ethnicity affects the structure of the real estate agency business. ${ }^{1}$ The results indicate that ethnic identification contributes a separate and distinct dimension to real estate agency practice, a dimension that should be included in explanations of real estate agent-seller relationships.

\section{Housing Market Segmentation By Race and Ethnicity}

Studies of residential patterns of Hispanics, blacks, and Anglos in American cities have documented the continuing pattern of housing market segmentation on racial or ethnic lines (Kain and Quigley 1975; Logan and Schneider 1984; Taeuber and Taeuber 1965; Wilson 1979; Yinger 1975). ${ }^{2}$ Residential segmentation by ethnicity may reflect either a choice on the part of

\footnotetext{
${ }^{1}$ In this paper, the term "ethnicity" is used to indicate both race and ethnic group membership.

${ }^{2}$ In this paper, membership in an ethnic group was approximated in a crude fashion: real estate agents were
} 
minorities to live apart from the host society or a constraint imposed by the host society in order to exclude minorities from adjacent residential space. To the extent that constraints on the residential mobility of minorities constitute a deprivation of opportunities for urban services, any discrimination-based restriction on residential choice is an issue for scholarly as well as policyrelated attention.

Evidence that ethnic segmentation of the housing market results from constraint can be gathered in two ways. One is to observe the in- direct effects of race on housing consumption. Such evidence includes observed differences in the type and quality of housing purchased by different racial groups when income and tastes have been controlled. A large literature on housing market discrimination has focused on differential prices paid for similar packages of housing by whites as opposed to blacks. Higher costs paid by minority homebuyers for a bundle of housing characteristics are explained by the argument that minorities are forced to pay a premium for housing at the boundary between minority and Anglo areas to permit the landowners to recoup from the eventual long-run decline in housing values there. It is therefore expected that house prices will be highest in Anglo areas and lowest in minority areas, with a temporary increase in values during the period of minority expansion (Berry 1976; Yinger 1975). A related line of reasoning explains white-black differences in house prices for comparable housing bundles on the basis of supply and demand: if there is discrimination against black buyers, the number of houses available for purchase by blacks will be smaller than that available to whites. With a similar demand curve and a smaller supply, blacks will pay more for similar housing. Remarkably, studies of price-attribute structures have come to highly varied conclusions as to whether or not white-black differentials exist (Lapham 1971; Daniels 1975; Straszheim 1974; King and Miewszkowski 1973). There does, however, seem to be some degree of consensus that blacks do pay more for similar housing (Wilson 1979).

The second method of determining whether racial discrimination exists in the housing market is through direct observation of racial differentiation in the treatment of buyers by sellers, their agents, or insurance and financial institutions. Several studies have tried to measure discrimination in housing markets directly through the observation of real estate agent behavior or home mortgage lending practice (Weinke, Reid, Simonson, and Eggers 1979). Interviews with real estate agents in the 1950s and 1960s showed that agents had strong opinions concerning their duty to "protect" neighborhoods by "placing" buyers in environments based, at least partially, on racial or ethnic characteristics (Barresi 1968; Cater 1981; Helper 1969). Although

\footnotetext{
classified as being Anglo, Hispanic, (based on surname) or black (based on skin color and racial association). The significance of ethnicity and perceived self-identification in an ethnic group were not probed in the interviews. Although this is a standard research procedure, this type of classification has conceptual weak- nesses, and may account for some of the variation in the responses of minority real estate agents. Minority real estate agents appear to be "marginal" in ethnic identity: that is, although they are considered to be minority group members by outsiders, they seem to have adopted a middle class, Anglo outlook in adapting to an Anglo-dominated occupational group. This marginality is illustrated by the tendency of minority agents to live outside minority-dominated neighborhoods, suggesting that minority agents may have adopted values more associated with their chosen profession than with minority group membership.
} 
such steering of buyers away from particular neighborhoods is now illegal and although it would be difficult now to obtain the kind of frank evaluations that Helper gathered from real estate agents, several studies documenting the treatment of homebuyers by southwest Chicago real estate agents have yielded evidence of race-based steering (Witt 1983, 20).

One explanation, then, for continued racial segregation in the urban housing market is racial segmentation in the business practices of real estate agents. Although discriminatory treatment of homebuyers by real estate agents has been studied, the structure of the real estate industry itself and the place of minorities in this industry is less well documented (Zonn 1980). The study reported here investigated the extent to which the real estate industry itself is segmented along racial or ethnic lines.

Previous research suggests the likelihood of such segmentation. Brown (1971) documented the marginal position of the black real estate agent in the white real estate establishment in his study of the history of participation of blacks in the Oakland Real Estate Board. He noted that white brokers rarely employed black salespersons and that blacks were excluded from the Oakland Board until 1962. Lake's study (1981) of suburban New Jersey real estate brokers revealed practices designed to ensure the continued existence of racial submarkets and the use of race as a criterion for filtering listings to sales prospects. He concluded that white brokers tended to discourage the entry of blacks into areas within which they worked, at least partly to protect these areas as sources of potential future clients.

If segmentation of the real estate business along ethnic lines exists, it is important to specify its nature and extent for several reasons. First, any such segmentation affects the amount and quality of information available to prospective homebuyers, adding to the migration decision a component that is unrelated to income and abetting the continued separation of ethnic or racial groups. Second, since real estate agents are key actors in the urban housing market (Pahl 1975), it is important to understand the factors affecting their provision of spatial information to prospective homebuyers.

In order to determine that there is ethnic segmentation within the real estate agency business, one would need clear evidence that the clientele and territories covered by real estate agencies with similar locations are clearly distinguished by ethnic characteristics. Three research hypotheses were devised to evaluate the strength of the relationship between ethnicity and real estate agent business practice: (1) sellers select real estate agents on the basis of a common ethnicity; (2) ethnicity affects the size and location of territories within which real estate agents search for listings; and (3) the network of business contacts of the real estate agent is limited and shaped by the ethnicity of the agent.

\section{The Study Area}

The study was conducted during the fall and winter of 1982 in the Denver metropolitan area 
(Fig. 1). The five-county metropolitan region had a population of approximately 1.6 million in 1980, including 78,000 blacks (4.9 percent) and 173,000 Hispanics (10.8 percent). The median family incomes for Anglos, blacks, and Hispanics were generally higher than those for the United States as a whole. As in other cities in the Southwest, the median family incomes of Hispanics were lower than those of both Anglos and blacks (James, McCummings, and Tynan 1983).

Suburbanization in this metropolitan area proceeded at a rapid rate during the 1970s. There was an increase of 355,000 suburban Anglo residents, 47,000 suburban Hispanic residents, and 16,000 suburban black residents, representing a percentage increase of this last population of 533 percent. Hispanics are mainly concentrated on the north and west portions of the city of Denver and its adjacent suburbs, including Westminster, Federal Heights, and Northglenn (Fig. 2). Blacks are mainly located in the eastern sector of the city near Stapleton International Airport, as well as eastern suburbs such as Aurora (Fig. 3).

In a study of southwest cities, Hispanics were shown to be less segregated from the majority population of white Anglos than were blacks (Massey 1979; Massey and Mullan 1984). Black segregation was also shown to be more likely to persist despite a rise in social class position, movement to the suburbs, or increase in the number of generations in a particular city for black households. James, McCummings, and Tynan (1983) calculated the extent to which blacks and Hispanics share residential space with Anglos in Denver in 1970 and 1980. They show that between 1970 and 1980, both blacks and Hispanics in Denver have increased their exposure rates to Anglos and "others," but have decreased in their exposure to one another. They also demonstrate that in Denver, as in other southwest cities, blacks are more segregated from Anglos than are Hispanics, and there is little residential mixture between blacks and Hispanics.

The survey was limited to five Boards of Realtors whose territories comprise the major portion of the built-up region of Denver and its immediate suburbs, excluding Boulder County. These five boards were the Denver Board of Realtors, the North Suburban Board, the South Suburban Board, the Jefferson County Board, and the Aurora Board. A field estimate indicated that of the approximately 6,600 real estate agents affiliated with these five boards, approximately 90 members were black and 80 were Hispanic (Grow 1984). The black real estate agents were affiliated primarily with two boards: 45 with the Aurora Board and 28 with the Denver Board. Hispanic real estate agents were affiliated primarily with the North Suburban Board (20 Hispanic agents) and the Denver Board (45 Hispanic agents). It is especially in these areas that Anglo real estate agents came into contact and competition with minority agents. 


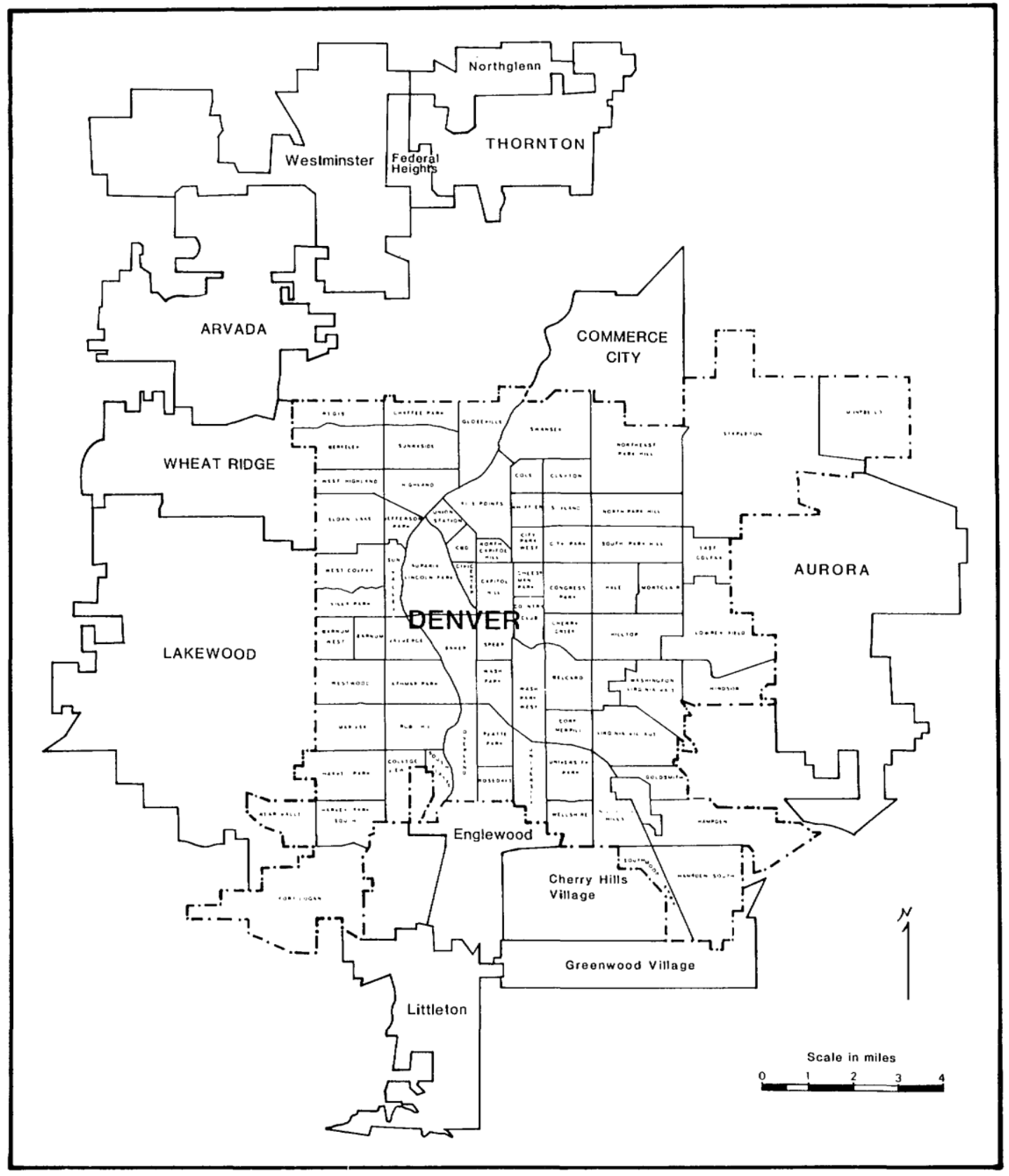

Figure 1. Denver neighborhoods and suburban areas. 


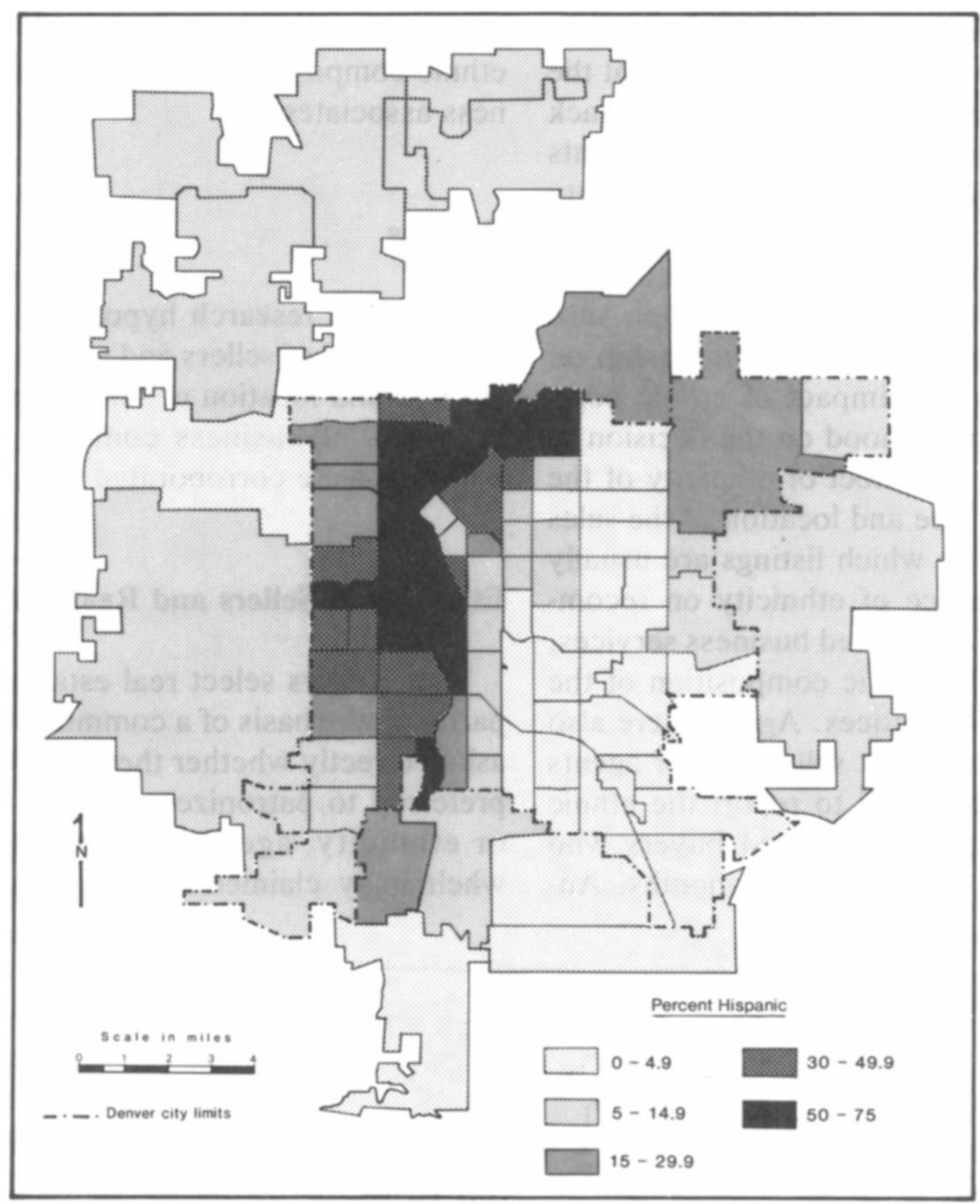

Figure 2. Denver area percentage Hispanic population: 1980. 


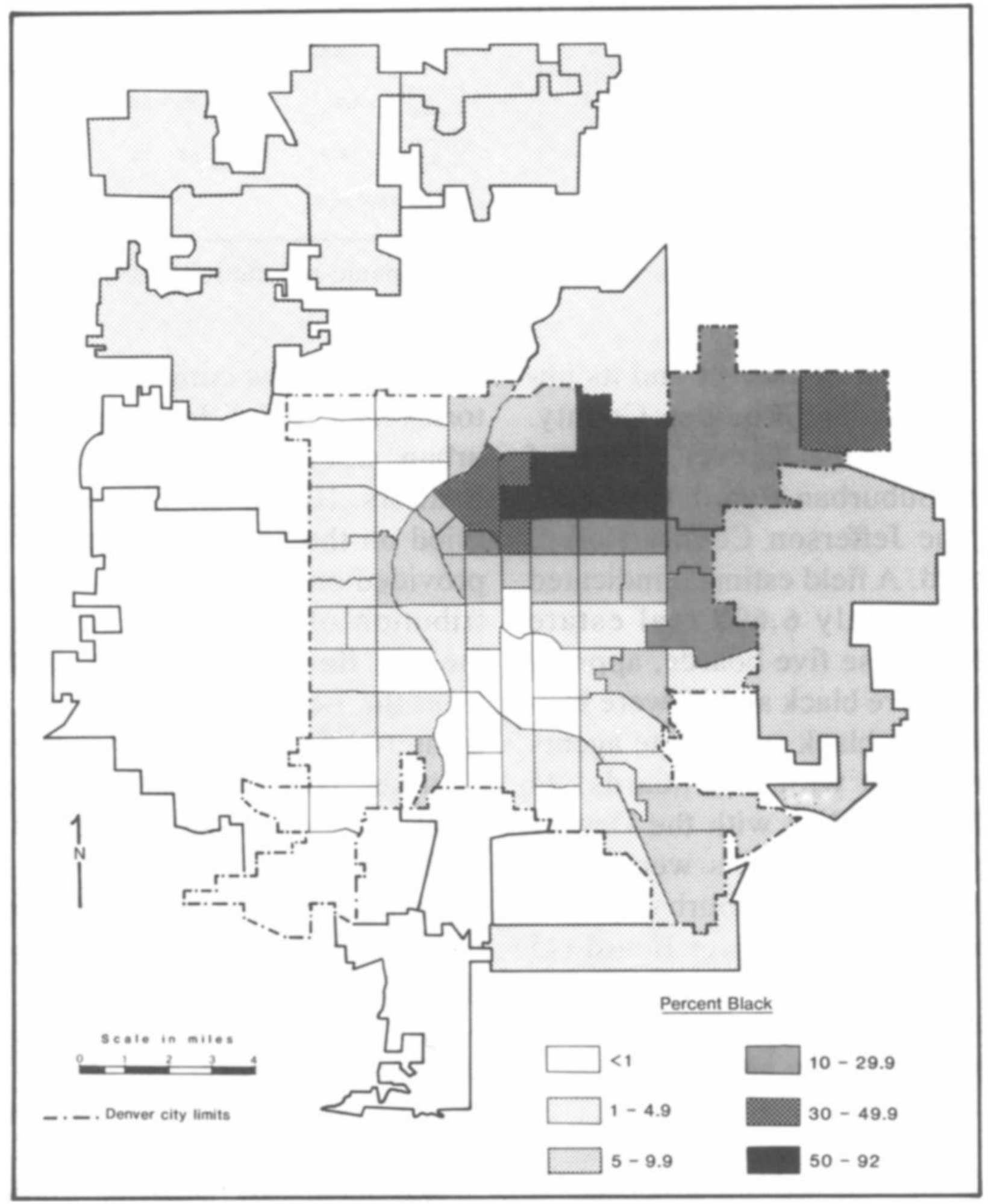

Figure 3. Denver area percentage black population: 1980. 


\section{Sampling}

A list of the names of real estate agents to be interviewed was compiled from the board directories for Denver. Jefferson County, North Suburban, South Suburban, and Aurora Boards of Realtors. Hispanic real estate agents were identified on the basis of surname, a technique that provided only a rough approximation of the distribution of this group. This list was supplemented through consultation with individuals from the League of United Latin American Citizens (LULAC) as well as through interviews with key Hispanic business leaders. The list of black real estate agents was obtained in consultation with the Denver Board of Realtists, a small and predominantly black organization affiliated with the National Association of Realtists. This list was augmented in consultation with key black real estate brokers and other community leaders. The Anglo sample was selected from the remaining nonminority population. ${ }^{3}$

This means of sampling minority agents was necessary in the absence of an ethnically sorted list but probably resulted in a distortion of the extent of connectivity among minority agents surveyed. On the other hand, I estimate that the sample includes about 50 percent of the black agents and 67 percent of the Hispanic agents currently selling real estate in the four-county region. Face-to-face interviews were completed with 50 Anglo, 50 Hispanic, and 45 black agents.

The survey questionnaire probed such subjects as the influence of board membership on business practices, the impact of ethnic composition of the neighborhood on the decision to do business there, the effect of ethnicity of the salesperson on the size and location of the sales territory, the ways in which listings are usually obtained, the influence of ethnicity on recommendations of specific related business services, and the effect of the ethnic composition of the agency on business practices. Agents were also asked if they believed that sellers prefer agents of the same ethnicity, and to report the ethnic composition of recent sellers and buyers who had used the firm in the past six months. Another set of questions dealt with the extent and ethnic composition of agent's networks of business associates.

\section{Results}

The three research hypotheses dealt with (1) the ethnicity of sellers and real estate agents; (2) the size and location of sales territories; and (3) networks of business contacts. All three hypotheses

\footnotetext{
${ }^{3}$ The Anglo sample was not a random sample of the remaining real estate agents but included a dis- proportionate number of Anglo agents from two Boards of Realtors in which there is direct ethnic competition in the same neighborhoods: Aurora and the suburbs to the north of the city limits within the North Suburban Board (Fig. 1).
} 
were corroborated by survey findings.

\section{Ethnicity of Sellers and Real Estate Agents}

First, sellers select real estate agents at least partly on the basis of a common ethnicity. When asked directly whether they believed that sellers preferred to patronize agents of the same race or ethnicity, agents of each ethnicity overwhelmingly claimed that race or ethnicity did not enter into the choice of an agent (Table 1). Their reasoning was complex. Some agents, particularly Anglos, stated that most people do not consider race or that the real estate agent is chosen on the basis of professional qualifications. Minority agents, however, were more likely to complain that some blacks or Hispanics go out of their way to patronize Anglo agents. One agent claimed, "There is a stigma about the black businessperson being incompetent, not being in business long enough, or somehow being less professional." Agents who stated that there is a tendency to patronize agents of the same racial or ethnic background explained that the choice was affected by the "ease of the relationship," or that "people feel more comfortable with people of the same race whether in marriage, social clubs, or anything else."

Table 1. Do You Think That Sellers Prefer To Patronize Real Estate Agents of the Same Race or Ethnicity?

\begin{tabular}{lcc}
\hline Ethnicity of Respondent & $\begin{array}{c}\text { No } \\
\text { (percentage) }\end{array}$ & $\begin{array}{c}\text { Yes } \\
\text { (percentage) }\end{array}$ \\
\hline Anglo $(\mathrm{N}=50)$ & 72.0 & 28.0 \\
Hispanic $(\mathrm{N}=50)$ & 88.0 & 12.0 \\
Black $(\mathrm{N}=45)$ & 75.6 & 24.4 \\
\hline
\end{tabular}

Despite real estate agents' assertion that ethnicity has nothing to do with the choice of an agent, their reports of the ethnic make-up of their own clientele indicates that ethnicity does affect agent choice. Although agents of all ethnic backgrounds dealt in large part with Anglo sellers, it was mainly black agents who had more than 20 percent black sellers and mainly Hispanic agents who had more than 20 percent Hispanic sellers (Table 2). All of the Anglo agents interviewed had at least 20 percent Anglo sellers among their recent clients, but only 83 percent of the black agents and 81 percent of the Hispanic agents had at least this percentage of Anglo clients. Similarly, only 25 percent of the Anglo agents and 6 percent of the Hispanic agents, but 78 percent of the black agents had black sellers accounting for at least one-fifth of their clientele.

Table 2. Ethnic Composition of Real Estate Agent Clients: Percent of Agents With More Than 20 Percent of Their Clients in Each Ethnic Group

\begin{tabular}{lccc}
\hline \hline & \multicolumn{3}{c|}{ Race of Seller } \\
\cline { 2 - 4 } $\begin{array}{l}\text { Race of } \\
\text { Agent }\end{array}$ & Anglo & Black & Hispanic \\
\hline Anglo & 100 & 25 & 17 \\
Black & 83 & 78 & 5 \\
Hispanic & 81 & 6 & 70 \\
\hline
\end{tabular}


It might be argued that this tendency to deal with clients of the same ethnicity is merely a function of distance from the home of the seller to the office of the agent: in other words, one might argue that because black real estate agents are located in black neighborhoods or because Hispanic agencies are in Hispanic neighborhoods, sellers are merely patronizing the neighborhood agency and not necessarily selecting an agency on the basis of common racial or ethnic background. To test for the effects of neighborhood or distance, offices located within the same Board of Realtors jurisdiction but having different ethnic/racial make-up were compared to determine whether the pattern of ethnic segmentation of patronization held up for offices in a single neighborhood.

The North Suburban Board, including the suburbs of Westminster, Northglenn, Thornton, and Arvada, is an area of direct competition between Hispanic and Anglo agencies (Fig. 1). To compare patronization of Hispanic agents vs. Anglo agents, offices in this board were selected for the same cross-tabulations of race of agent and race of client. This tabulation (Table 3) revealed the greater patronization of Hispanic agents by Hispanic sellers, despite the presence of nearby Anglo agencies. Although 80 percent of the Anglo real estate agents reported that 20 percent or fewer of their seller-clients were Hispanics, only 36 percent of Hispanic real estate agents reported such low percentages of Hispanic clients. Similarly, only 20 percent of the Anglo real estate agents reported that over 21 percent of their clientele (sellers) were Hispanic, whereas about two-thirds of the Hispanic agents reported that over 20 percent of their clientele were Hispanic. Similar results were observed for the patronization of agents by Anglo sellers. Although almost 20 percent of the Hispanic real estate agents indicated that fewer than 40 percent of their clients were Anglos (not shown in Table 3), none of the Anglo real estate agents claimed that only a minority of their clients were Anglos.

The Aurora Board of Realtors deals with listings mainly in the suburb of Aurora (Fig. 1). Competition between black and Anglo agents was assessed by comparing clientele of Aurora Board agents (Table 4). Despite the presence of both Anglo and black agencies in this single suburban cluster, there was a tendency for black buyers to patronize black agents. Analysis of the patronization of real estate agents by Anglo sellers yields similar results; although only 8 percent of Anglo real estate agents claimed that fewer than 40 percent of their sellers were Anglo, 39 percent of the black agents indicated that such a minority of their clients was Anglo. These detailed cross-tabulations provide evidence that sellers do not select agencies purely on the basis of office proximity. Instead, it appears that sellers, when given a choice among real estate agents of different ethnicities but similar locations, tend to patronize agents of the same ethnic identity. Thus, despite real estate agents' denial that ethnicity is a factor in a seller's selection of an agent, there is evidence in the patterns of agent patronization that ethnicity does enter a seller's decision to list with a particular agent. Furthermore, this pattern persists, even in areas where there is direct competition between Anglo and Hispanic or Anglo and black agencies. Sellers are not listing with an agency simply because it is located in the local neighborhood; they are expressing an ethnic preference in their behavior. 
Table 3. Patronization of Real Estate Agents by Hispanic Sellers in the North Suburban Board of Realtors

\begin{tabular}{lccc}
\hline & \multicolumn{3}{c}{$\begin{array}{c}\text { Percentage of clientele } \\
\text { that was Hispanic }\end{array}$} \\
\cline { 2 - 4 } Ethnicity of & $0-20$ & $21-61$ & $61-100$ \\
Agent & $80^{\mathrm{a}}$ & 20 & 0 \\
Anglo & 36 & 55 & 9 \\
\hline
\end{tabular}

a Percent of Anglo agents reporting that less than 20 percent of their clientele was Hispanic.

\section{Size and Location of Territories}

The second hypothesis was that ethnicity or race affects the size and location of the territory that real estate agents comb for listings. This hypothesis was tested with two sets of data. The first was based on a survey question that asked the respondent to list the "factors that are important in determining the extent of your sales territory-that is, what prevents you from doing business in certain areas and what encourages you in doing business in others." No race-related prompt was attached to this question. Most Anglo and Hispanic respondents mentioned familiarity with the area or distance from home or office as the primary factors limiting their territories. Blacks were far more likely to indicate the importance of the racial composition of the neighborhood, particularly when they were dependent on door-to-door solicitations for new listings. One black agent stated, "It is difficult for me to get listings in the south suburban area; you don't just go out and get listings looking like me. I don't care how qualified you are." Similarly, an Anglo agent working in a racially mixed firm with a black broker admitted that if she suspected that a caller was black on the basis of accent or voice, she would refer the caller to one of the firm's black salespersons because she feared the "high crime" associated with black neighborhoods.

Table 4. Patronization of Real Estate Agents in the Aurora Board of Realtors by Black Sellers

\begin{tabular}{lccc}
\hline \hline & \multicolumn{3}{c}{ Percentage of clientele that was black } \\
\cline { 2 - 4 } Ethnicity of & $0-20$ & $21-61$ & $61-100$ \\
Agent & 31 & 69 & 0 \\
Anglo & 38 & 56 & 6 \\
Black & &
\end{tabular}

Additional evidence of the effects of race or ethnicity on the size and extent of the territory covered by the agent was provided by an analysis of listings for agents in a single company. Current listings published in the Multiple Listing Service book for early 1982 were compared for agents in a large integrated firm that was affiliated with an intercity real estate network. Listings for Anglo and black agents of this firm, whose office was located in suburban Aurora, were 
tabulated and their locations were compared. The resulting tabulations (Fig. 4) show that black real estate agents were far more likely to obtain listings from neighborhoods that were at least 40

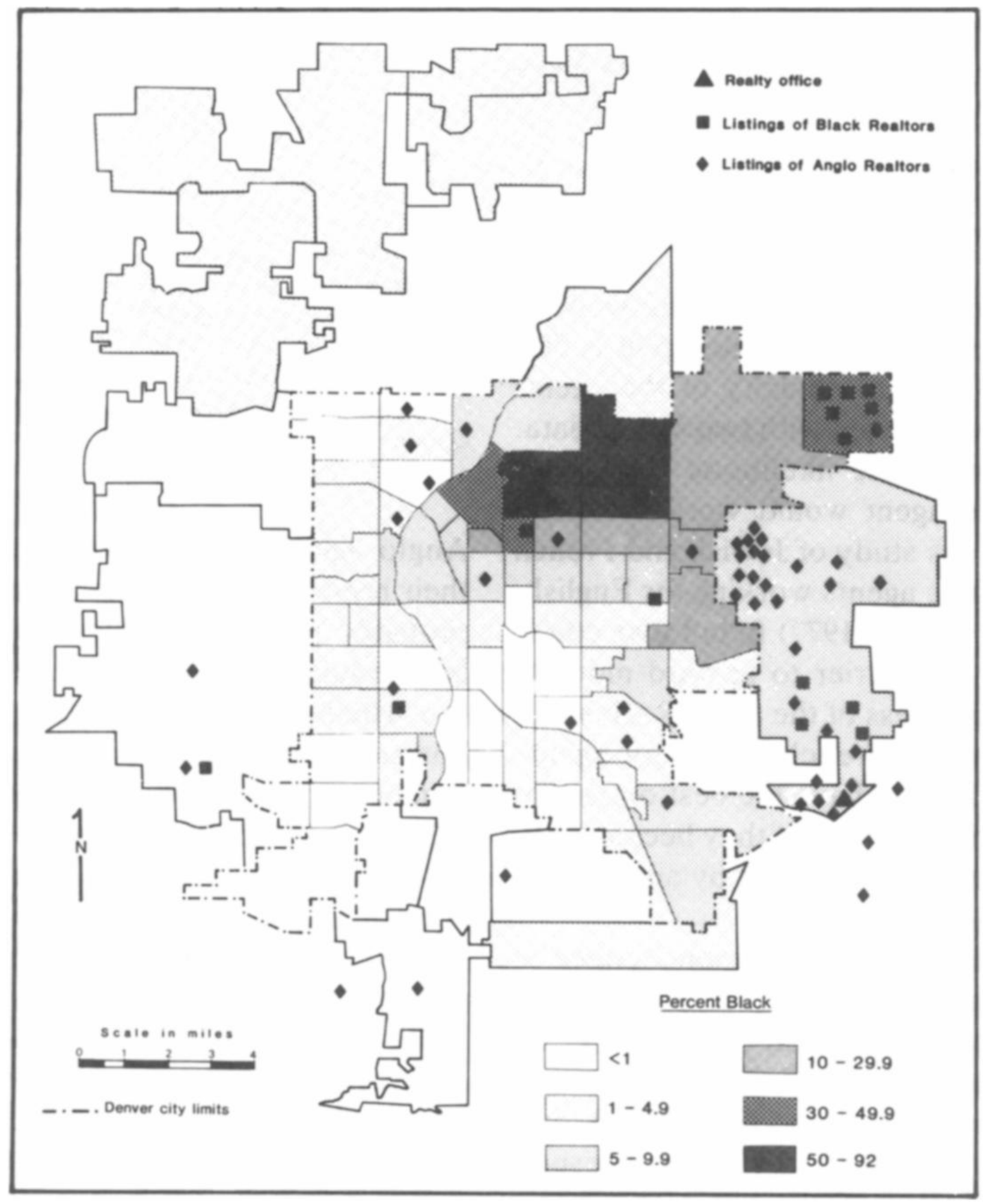

Figure 4. Listings of Anglo and black realtors from a single Aurora realty office: 1982. 
percent black than were Anglo agents, and Anglo agents were far more likely to obtain listings from neighborhoods that were less than 10 percent black (Table 5). As the office location for these agents was the same, these differences are most likely attributable to the race of the agent rather than to the location of the office.

The issue of whether black agents perceive this situation as advantageous-guaranteeing them a portion of a market-or disadvantageous-excluding them from a portion of a market-cannot be ascertained from the available data. A calculation of the median value of housing listed by Anglo and black agents in the same firm, however, gives some indication of their relative status. The median listing price for houses handled by Anglo agents in this firm was $\$ 79,000$, whereas the median listing price for houses handled by black agents was only $\$ 65,000$. The black agent sold houses in a more circumscribed territory and at markedly lower prices, generating less commission. Regardless of perception, therefore, the black agent does seem to be at a business disadvantage in the ethnically and racially segmented housing market.

Table 5. Numbers of Listings Obtained by Anglo and Black Agents Employed by a Single Firm

\begin{tabular}{ccccccc}
\hline \hline & \multicolumn{5}{c}{ Percentage black in the neighborhood } \\
\cline { 2 - 7 } Race of & $0-1$ & $1-5$ & $5-10$ & $10-17$ & $39-49$ & $71-92$ \\
Agent & percent & percent & percent & percent & percent & percent \\
\hline Black & 1 & 1 & 5 & 0 & 14 & 9 \\
Anglo & 12 & 4 & 28 & 2 & 1 & 0 \\
\hline
\end{tabular}

Anglo and Hispanic agents are less likely to sense the significance of race or ethnicity as a factor that limits the size of their sales territory; they are also unlikely to suffer serious business setbacks by their possible inability to obtain listings in the relatively small portion of Denver occupied by black homebuyers. However, black agents are highly aware of the fact that this factor limits their sales territory. Furthermore, maps of the actual territories from which listings are obtained demonstrate the impact of race or ethnicity on the size and location of the sales territory, given a common office location.

\section{Networks of Business Contacts}

The third hypothesis was that the network of business contacts of the real estate agent is limited and shaped by the ethnicity of the agent. This hypothesis was tested with two sets of data. The first concerned the likelihood that a minority real estate agent would work for a minority broker. In his study of Jewish and French Canadian real estate agents working for English- Canadian firms, House (1977) found that ethnic identification was a barrier to upward mobility in such firms, regardless of the agent's sales performance. Jewish or French Canadian agents were therefore likely to have the best opportunities for managerial positions if they became selfemployed or sought employment by another minority broker. 
In Denver, real estate salespersons tended to work for brokers of the same race or ethnicity. Seventy percent of the Anglo salespersons interviewed worked for Anglo brokers, 93 percent of the black salespersons worked for black brokers, and 74 percent of the Hispanic salespersons worked for Hispanic brokers. The Anglo estimate may even underestimate the extent to which Anglos are employed by Anglos because of the way in which the sample was drawn. There is relatively little interethnic employment; salespersons tend to be of the same ethnic or racial characteristics as the brokers for whom they work.

The impacts of ethnicity on business contacts was corroborated by a survey question asking the real estate agents to name the five other agents whom they most respect and whose ethical practices and business standards most approach their own ideals (Table 6). Percentages "expected" in each category were based purely on the percentages of Board members of each ethnic group in the four-county region in which the survey was conducted. In other words, only slightly more than 1 percent of all real estate agents were Hispanic or black; therefore, one would "expect" that such agents would be named only 1 or 2 percent of the time.

In response to this question, Anglo, black, and Hispanic agents overwhelmingly named other agents of the same ethnic background. Based on total percentage of each group in the total population of real estate agents in the four-county area. Anglo agents named fewer other Anglos than their representation in the general population- probably partially a reflection of the tendency for the sample to include Anglos with more than the usual amount of contact with blacks and Hispanics. However, minority agents disproportionately named other minorities. Blacks named other blacks about two-thirds of the time, and Hispanics named other Hispanics about half of the time. Anglos were the second most frequently named group for both blacks and Hispanics, with Hispanics almost never naming black agents. This pattern reflects both the numerical dominance of the real estate industry by Anglos and the tendency for only slight mutual acquaintance between blacks and Hispanics.

Table 6. Agents Known and Respected

\begin{tabular}{lccc}
\hline & \multicolumn{3}{c}{ Race of agent named (Percentage) } \\
\cline { 2 - 4 } Race of & Anglo & Black & Hispanic \\
\hline Respondent & 87.0 & 7.5 & 5.5 \\
Black & 32.0 & 66.6 & 1.3 \\
Hispanic & 53.9 & 0.6 & 45.5 \\
Expected $^{a}$ & 97.4 & 1.3 & 1.2 \\
\hline
\end{tabular}

a Based on total percentage of each group in the total population of real estate agents in the four-county area. 


\section{Conclusion}

Survey data, supplemented by the mapping and statistical analysis of current listings for members of the Denver and suburban Board of Realtors members, suggests that there is a distinct effect of ethnicity or race on the business practices and business contacts of real estate agents. Analysis of the pattern of listings reported by agents in the same general neighborhood, as well as agents of different ethnic-racial background working for the same office indicates that sellers seem to exhibit a pattern of preference not only for local real estate agents, but also for real estate agents of the same ethnic background. Second, ethnicity affects both the size and location of territories in which real estate agents seek new listings, and this generalization is especially true for black agents who feel particularly limited in attempting to seek listings in white dominated areas. Finally, real estate agents tend to know and professionally respect other agents of the same ethnic background; black agents tend to know other black agents, and Hispanic agents tend to know more Hispanic agents.

The general classification of agents into ethnic or racial groups used in this research was sufficient to capture the division of the housing market into distinct territories and networks of business contacts. However, research on the notion of ethnicity and race suggests that a more complex and sensitive notion of ethnic identity would be more appropriate to illuminate the ways in which real estate agents apportion the market along racial and ethnic lines. An investigation of the ethnic self-identification of real estate agents would contribute to a better understanding of the ways in which the practices of this profession contribute to continuing pat- terns of ethnic division of residential space.

Acknowledgments

Funding for this project was provided by the National Science Foundation through grant SES8210972. Any opinions, findings, conclusions or recommendations expressed in this paper are those of the author and do not necessarily reflect the views of the National Science Foundation. Additional support was provided by the University of Colorado Council on Research and Creative Work. The project was completed when the author was a member of the professional staff of the Institute of Behavioral Science at the University of Colorado. The primary research assistant on this project was Claudia Grow, who was also assisted by Chris Daly and Patricia Harrison. Cartography was done by Andrew Giammarco. The manuscript was revised on the basis of helpful suggestions from William A.V. Clark, James Huff, Andrew Kirby, Robert Lake, and Robin Ward. 


\section{References}

Barresi, C. 1968. The role of the real estate agent in residential location. Sociological Focus 1:59-71.

Berry, B. J. L. 1976. Ghetto expansion and single- family housing prices: Chicago, 1968-72. Journal of Urban Economics 3: 397-423.

Brown, W. H. 1971. Access to housing: the role of the real estate industry. Economic Geography 48: 68-78.

Caruso, D. J. 1976. Neighborhood search, residential evaluation, and the housing market. Unpublished paper, Department of Geography, University of Minnesota.

Cater, J. 1981. The impact of Asian estate agents on patterns of ethnic residence: a case study of Bradford. In Social interaction and ethnic segregation, ed. P. Jackson and S. J. Smith, pp. 163-84. London: Academic Press.

Clark, W. A. V., and Smith, T. 1979. Modelling information use in a spatial context. Annals of the Association of American Geographers 69:575-88.

Daniels, C. B. 1975. The influence of racial segregation on housing prices. Journal of Urban Economics 2:105-22.

Grow, C. 1984. Ethnic characteristics of realtor net- works in the Denver metropolitan region. Master's thesis, Department of Geography, University of Colorado, Boulder.

Helper, R. 1969. Racial policies and practices of real estate brokers. Minneapolis: University of Minnesota Press.

House, J. D. 1977. Contemporary entrepreneurs: the sociology of residential real estate agents. Westport: Greenwood Press.

James, F. J.; McCummings, B. L.; and Tynan, E. A. 1983. Discrimination, segregation and minority housing conditions in sunbelt cities: a study of Denver, Houston and Phoenix. Denver: Center for Public-Private Sector Cooperation, Graduate School of Public Affairs, University of Colorado, Denver.

Kain, J. F., and Quigley, J. M. 1975. Housing markets and racial discrimination: a microeconomic analysis. New York: National Bureau of Economic Research.

King, A. T., and Miewszkowski, P. 1973. Racial discrimination segregation, and the price of housing. Journal of Political Economy 81:590-606.

Lake, R. W. 1981. The new suburbanites: race and housing in the suburbs. New Brunswick: Center for Urban Policy Research, Rutgers University. 
Lapham, V. 1971. Do blacks pay more for housing? Journal of Political Economy 79:1244-57.

Logan, J. R., and Schneider, M. 1984. Racial segregation and racial change in American suburbs, 1970-1980. American Journal of Sociology 89:874-88.

Massey, D. S. 1979. Effects of socioeconomic factors on the residential segregation of blacks and Spanish Americans in U.S. urbanized areas. American Sociological Review 44:101522.

Massey, D. S., and Mullan, B. P. 1984. Processes of Hispanic and black spatial assimilation. American Journal of Sociology 89:836-73.

Pahl, R. E. 1975. Whose city? 2d ed. Harmondsworth: Penguin Books.

Palm, R. I. 1976. Real estate agents and geographical information. Geographical Review 66:26680.

Straszheim, M. 1974. Hedonic estimation of the housing market prices: a further comment. Review of Economics and Statistics 56:404-6.

Taeuber, K. E., and Taeuber, A. F. 1965. Negroes in cities: residential segregation and neighborhood change. Chicago: Aldine.

Wienk, R.; Reid, C.; Simonson, J.; and Eggers, F. 1979. Measuring racial discrimination in American housing markets: the housing market practices survey. Washington, D. C.: U.S. Department of Housing and Urban Development.

Wilson, F. D. 1979. Residential consumption, economic opportunity, and race. New York: Academic Press.

Witt, H. 1983. Decoys accuse realty agents of 'steering'. Chicago Sunday Tribune, November 13, 1983, section 4, page 1 .

Yinger, J. 1975. The black-white price differential in housing: some further evidence. Discussion paper 308-75, Institute for Research on Poverty, Madison, Wisconsin.

Zonn, L. E. 1980. Information flows in black residential search behavior. Professional Geographer32:43-50. 